\title{
BMJ Open Transfusion of red blood cells in patients with traumatic brain injuries admitted to Canadian trauma health centres: a multicentre cohort study
}

\author{
Amélie Boutin,, ${ }^{1,2}$ Lynne Moore, ${ }^{1,2}$ François Lauzier, ${ }^{1,3}$ Michaël Chassé, ${ }^{1,3}$ \\ Shane English, ${ }^{4}$ Ryan Zarychanski, ${ }^{5}$ Lauralyn Mclntyre, ${ }^{4}$ Donald Griesdale, ${ }^{6}$ \\ Dean A Fergusson, ${ }^{4}$ Alexis F Turgeon ${ }^{1,3}$
}

To cite: Boutin A, Moore L, Lauzier $\mathrm{F}$, et al. Transfusion of red blood cells in patients with traumatic brain injuries admitted to Canadian trauma health centres: a multicentre cohort study. BMJ Open 2017;7:e014472. doi:10.1136/bmjopen-2016014472

- Prepublication history and additional material is available. To view please visit the journal (http://dx.doi.org/ 10.1136/bmjopen-2016014472).

Received 26 September 2016 Revised 17 February 2017 Accepted 27 February 2017

CrossMark

For numbered affiliations see end of article.

Correspondence to Dr Alexis F Turgeon; alexis.turgeon@fmed. ulaval.ca

\section{ABSTRACT}

Background: Optimisation of healthcare practices in patients sustaining a traumatic brain injury is of major concern given the high incidence of death and longterm disabilities. Considering the brain's susceptibility to ischaemia, strategies to optimise oxygenation to brain are needed. While red blood cell (RBC) transfusion is one such strategy, specific RBC strategies are debated. We aimed to evaluate RBC transfusion frequency, determinants of transfusions and associated clinical outcomes.

Methods: We conducted a retrospective multicentre cohort study using data from the National Trauma Registry of Canada. Patients admitted with moderate or severe traumatic brain injury to participating hospitals between April 2005 and March 2013 were eligible. Patient information on blood products, comorbidities, interventions and complications from the Discharge Abstract Database were linked to the National Trauma Registry data. Relative weights analyses evaluated the contribution of each determinant. We conducted multivariate robust Poisson regression to evaluate the association between potential determinants, mortality, complications, hospital-to-home discharge and RBC transfusion. We also used proportional hazard models to evaluate length of stay for time to discharge from ICU and hospital.

Results: Among the 7062 patients with traumatic brain injury, 1991 patients received at least one RBC transfusion during their hospital stay. Female sex, anaemia, coagulopathy, sepsis, bleeding, hypovolemic shock, other comorbid illnesses, serious extracerebral trauma injuries were all significantly associated with RBC transfusion. Serious extracerebral injuries altogether explained $61 \%$ of the observed variation in RBC transfusion. Mortality (risk ratio (RR) 1.23 (95\% Cl 1.13 to 1.33)), trauma complications (RR 1.38 $(95 \% \mathrm{Cl} 1.32$ to 1.44$))$ and discharge elsewhere than home (RR 1.88 (95\% Cl 1.75 to 2.04)) were increased in patients who received RBC transfusion. Discharge from ICU and hospital were also delayed in transfused patients.

Conclusions: RBC transfusion is common in patients with traumatic brain injury and associated with

\section{Strengths and limitations of this study}

- This study was conducted using a large data set from the inclusive Canadian trauma systems.

- We explored a large spectrum of a priori conceptual models of the potential relationship between transfusions and clinical variables.

- Although residual confounding remains a concern, we optimised control for potential bias.

- We, however, could not perform any evaluation of the impact of haemoglobin thresholds on red blood cell transfusions.

unfavourable outcomes. Trauma severity is an important determinant of RBC transfusion. Prospective studies are needed to further evaluate optimal transfusion strategies in traumatic brain injury.

\section{INTRODUCTION}

Traumatic brain injury is a major cause of death and long-term disabilities. ${ }^{1-6}$ Caring for the most severe cases, usually admitted to the intensive care unit (ICU), requires significant and costly healthcare resources. ${ }^{1}{ }^{8} 8$ Care provided to this specific ICU population is the subject of significant research with the aim to establish best practice. Since brain oxygenation is associated with secondary brain injuries, ${ }^{9}{ }^{10}$ increasing cerebral oxygen delivery by maintaining higher levels of haemoglobin, through transfusion of red blood cells, has been suggested..$^{911}$ The presumed benefits of red blood cell transfusion, however, might be counterbalanced by potential harms due to inflammatory, thrombotic and immunological effects of transfusion, many of which are not well understood. ${ }^{10} 12$

Even though optimal transfusion strategies in this population are uncertain and clinical 
equipoise exists, ${ }^{4} 10$ 13-18 blood products are frequently administered to patients who have sustained a traumatic brain injury, with approximately a third receiving red blood cells according to our previous systematic review. $^{2} 19$ Significant practice variation is also observed. ${ }^{19}{ }^{20}$ Furthermore, little is known regarding potential determinants of transfusions, most cohort studies on transfusion in traumatic brain injury having reported no data or only descriptive statistics of potential determinants. ${ }^{19}$ Also, red blood cell transfusion has been shown to be associated with ICU and hospital lengths of stay in various population, ${ }^{21-24}$ even after adjustment for age, trauma or pathology severity and comorbidities. One trial and a subgroup of a large trial conducted specifically in patients with traumatic brain injury ${ }^{25}$ have failed to show significant differences in patient-oriented outcomes between transfusion strategies (transfusion at a high haemoglobin level compared with a low haemoglobin level). Best practices to guide optimal use of red blood cell transfusion in this population remain unclear ${ }^{19}{ }^{20}$ and further analyses of the current transfusions practices, their determinants and associated outcomes are needed to best inform the design of a future clinical trial.

The objective of our study was to estimate the frequency of red blood cell transfusion in patients with traumatic brain injury across Canadian health centres. Our secondary aim was to explore potential determinants of and clinical outcomes associated with transfusion. Finally, we wanted to examine effect modification by age, comorbidities and severity of traumatic brain injury on these associations.

\section{METHODS}

\section{Study design, setting and participants}

We conducted a retrospective cohort study of patients with a moderate to severe traumatic brain injury admitted to Canadian trauma centres. The study was reported in accordance to the Strengthening of the Reporting of Observational Studies in Epidemiology (STROBE) statement. $^{27}$

Patients were identified in the Canadian National Trauma Registry, which is maintained by the Canadian Institute for Health Information (see online supplementary appendix A for eligibility criteria of the registry). Records from the registry were linked to the Discharge Abstract Database, also maintained by the Canadian Institute for Health Information. The Discharge Abstract Database does not include data from the province of Québec.

Adult patients (aged $\geq 18$ years old) with a moderate or severe traumatic brain injury defined using International Classification of Diseases codes (ICD-10 S06), and Glasgow Coma Scale (GCS) scores $(<13)$ or intubated on admission, admitted to one of the centres participating to the registry (see online supplementary appendix A) between April 2005 and March 2013 were eligible. Since data pertaining to transfusions were collected from the Discharge
Abstract Database, patients whose records could not be linked to the database were excluded.

\section{Variables}

Our primary objective and exposure of interest was the frequency of red blood cell transfusion, which was available in the Discharge Abstract Database as a dichotomous variable indicating if a patient had received or not received a transfusion at any time during hospitalisation. Our secondary objectives were to identify the potential determinants of transfusion. Variables related to age, sex, brain injury severity (GCS scores), extracerebral injuries (measured by the Abbreviated Injury Scale $(\mathrm{AIS})^{28}$ ), on-admission comorbidities such as anaemia, bleeding, coagulopathy, sepsis, hypovolemic shock, ischaemic heart disease and cerebrovascular disease (identified with ICD-10 codes according to the literature, ${ }^{29} 30$ list provided in online supplementary appendix B), and surgical procedures (identified using Canadian Classification of Health Interventions (CCI) codes, list provided in online supplementary appendix $\mathrm{C}$ ) were extracted. Those variables were also potential confounding factors in the analysis of clinical outcomes. Our tertiary objectives were to evaluate the potential effect of red blood cell transfusion on clinical outcomes, that is, mortality, complications (defined previously in the literature $^{31} 32$ using ICD-10 codes, list provided in online supplementary appendix D), discharge destinations (home or elsewhere), length of hospital stay, length of ICU stay and duration of mechanical ventilation.

When a patient had been admitted to more than one centre for the same injury (eg, transferred from one hospital to another), we aggregated data from both hospital stays and considered it as one trauma hospital stay. For descriptive purposes and when considering cluster effects related to hospitals, we used data from the centre with the highest level of care.

\section{Statistical analysis}

\section{Primary objective: frequency of red blood cell transfusion}

We computed the overall incident proportion of patients with traumatic brain injury that received at least one red blood cell transfusion and its 95\% CI.

\section{Secondary objective: potential determinants}

We conducted multivariable analyses to identify baseline factors associated with red blood cell transfusion, including age, sex, comorbidities, traumatic brain injury severity (GCS and head AIS), and serious extracerebral injuries. We constructed robust Poisson models, ${ }^{33}$ with $\log$ link and random intercept at the centre level to take into account the variation in transfusion practices across centres. The final model included all potential determinants identified.

We computed relative weight analyses based on logistic models to evaluate of relative strength of each identified variable associated with transfusion, individually and when grouped according to the nature of the variable 
(pertaining to patient characteristics or trauma characteristics). The analysis uses variable transformations and creates sets of predictors that are orthogonal to one another in order to compute standardised weights, ${ }^{34}$ and allowed evaluating the importance of each predictor and their contribution relative to each other in the variation explained by the model.

A SAS macro created by Tonidandel in collaboration with Breton was used to compute the relative weights.

Considering that surgical procedures or interventions associated with bleeding may have occurred after transfusion or may be intermediate factors of multiple causal paths, we did not include them in our main models, but rather constructed alternative models adding an intervention indicator.

\section{Tertiary objective: patients' clinical outcomes}

We constructed a robust generalised linear mixed model with a Poisson distribution, log link and random intercept at the centre level to evaluate the association between red blood cell transfusion and mortality, presence of at least one trauma complication or hospital-to-home discharge, while adjusting for the previously identified baseline factors (ie, potential determinants of transfusion and confounders).

We evaluated the association between red blood cell transfusion and lengths of ICU and hospital stay with crude mean differences and as the distribution of length of stay was right-skewed, we used a log-transformation and computed adjusted geometric mean ratios in survivors.

Since we considered a short length of stay better than a longer stay and death can shorten hospitalisation, lengths of stay analyses were primarily limited to survivors. In order to avoid the exclusion of patients who died, with length of stay contingent on survival, ${ }^{35}$ a secondary analysis considered death at discharge in the model. Deaths were equivalent to indefinite stay (the longest ICU stay or hospital stay observed, ${ }^{36}{ }^{37}$ ie, 400 and 620 days respectively, with censoring at the end of observation). We constructed proportional hazard models of time to discharge from ICU or hospital, censoring death. ${ }^{37}$ We computed the inverse of HRs of ICU and hospital discharge to obtain a measure that would be $>1$ for unfavourable outcome (lower hazard of being discharged alive; longer stay), and $<1$ for favourable outcome (higher hazard of being discharged; shorter stay).

We evaluated association between transfusions and mechanical ventilation duration using multivariable mixed log-linear model, taking into account the cluster effect at centre level. We obtained adjusted geometric mean ratios and their $95 \%$ CIs.

\section{Effect modification/stratified analyses}

We conducted exploratory stratified analysis according to age, comorbidities and traumatic brain injury severity (moderate (GCS 9-12) or severe (GCS 3-8)), these factors being considered potential effect modifiers of the association between red blood cell transfusion and clinical outcomes by the study expert committee. We considered specific groups of baseline comorbidities (ischaemic heart disease, cerebrovascular disease, sepsis and septic shock, hypovolemic shock, bleeding, coagulopathy, anaemia identified using ICD-10 codes) in order to account, at least partially, for clinical heterogeneity of the pathological processes associated with different groups of comorbidities.

\section{Sensitivity analyses}

In a sensitivity analysis, lengths of stays were evaluated among survivors only and we reconducted the analyses for binary outcomes after excluding patients who died within 24, 48 and 72 hours of trauma since most withdrawal of life-sustaining therapy happened in a short window after trauma ${ }^{6}$ and death would therefore not be related to transfusion practices, but other factors such as goals of care for which we had no information.

\section{Treatment of missing data}

Multiple imputation was used for the treatment of missing GCS data. Ten data sets per imputation process were created. We used Markov chain Monte Carlo method, based on a multivariate normal model with 1000 chain iterations. Since GCS is an ordinal variable, we created dummy variables, imputed their values, and transformed them back into an ordinal scale by comparing them to the observed distribution of GCS scores. ${ }^{38} 39$

All analyses were conducted using SAS statistical software packages (V.9.3, SAS Institute, Cary, North Carolina, USA). A type I error of $5 \%$ was considered.

\section{RESULTS}

Among the 58251 patients that could be linked to Discharge Abstract Database data, 7062 were adult patients with moderate or severe traumatic brain injury or intubated on arrival (see figure 1-flow diagram and table 1). Most included patients were admitted in trauma centres situated in Ontario $(\mathrm{n}=3327 ; 47.1 \%)$ or Alberta ( $\mathrm{n}=1809 ; 25.6 \%)$; others were admitted in British Columbia $(n=1313 ; 18.6 \%)$, Nova Scotia $(n=415$; $5.9 \%)$, New Brunswick ( $\mathrm{n}=152 ; 2.2 \%)$ and Saskatchewan $(\mathrm{n}=46 ; 0.7 \%)$. No data from Prince Edward Island were available. Trauma admissions from Manitoba and Newfoundland could not be linked to the Discharge Abstract Database data due to invalid or missing health card numbers. Hospital admissions from the province of Québec do not contribute to the Discharge Abstract Database and therefore could not be linked. Most patients were admitted to a level I or II trauma centre (95.8\%). Mean age was 48.7 years old (SD 21.7) and most patients were men (73.2\%). Median ISS was 26 (IQR 25-36). More than half of included patients were intubated on arrival $(55.2 \%)$. Most patients $(78.0 \%)$ did not have any identified comorbidities recorded in the 


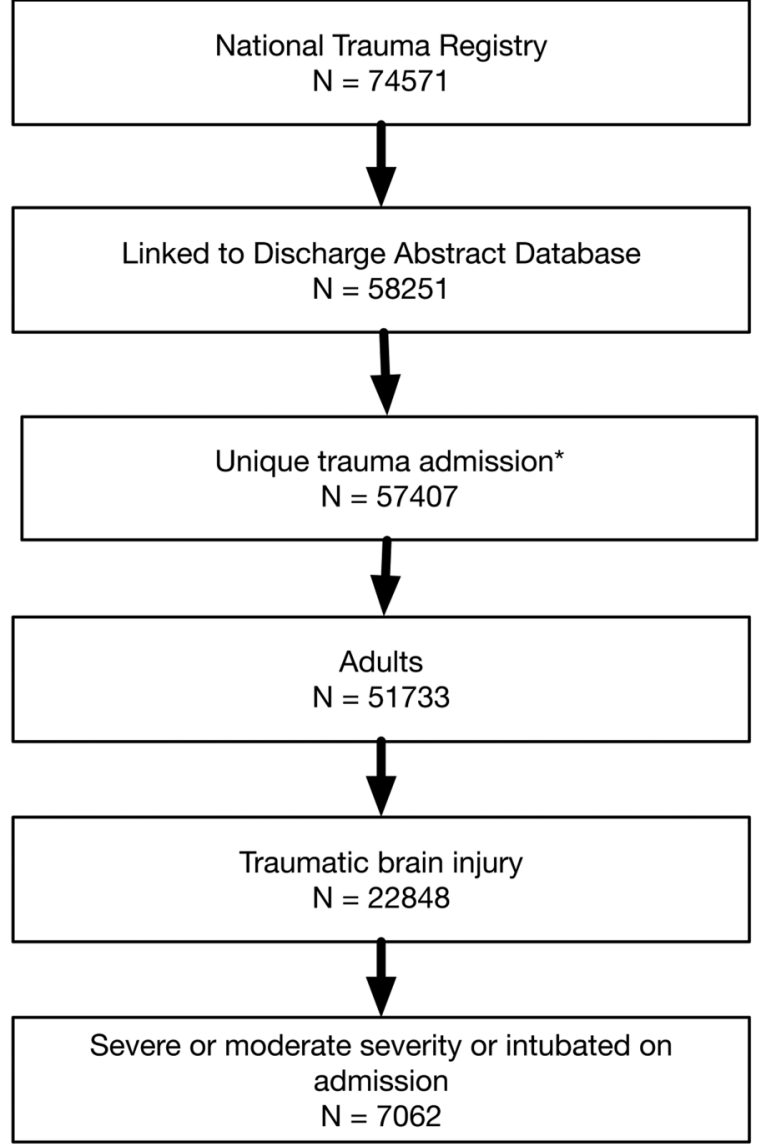

Figure 1 Flow diagram. *Admissions to more than one hospital for the same injury (transfers) were combined to consider only one trauma admission.

registry. The majority of patients sustained three or more injuries $(\mathrm{n}=5047,71.5 \%)$.

\section{Red blood cell transfusion frequency}

Overall, 1991 patients (28.2\%; $95 \%$ CI $27.2 \%$ to $29.3 \%$ ) received at least one red blood cell transfusion during their hospital stay. The proportion of patients receiving a red blood cell transfusion varied considerably across centres, $0-43 \%$. Level I and II trauma centre admissions were associated with the highest frequencies $(28.9 \%$ and $31.0 \%$, respectively), while level III-IV had $3.4 \%$ of patients transfused. Red blood cell transfusion also varied between provinces from $16.6 \%$ to $34.9 \%$.

\section{Potential determinants}

Female sex, age, anaemia, coagulopathy, sepsis, bleeding, hypovolemic shock, presence of other comorbidities, GCS $<9$, serious trauma to the face, thorax-abdomen, spine, upper and lower limbs were significantly associated with greater frequency of red blood cell transfusion according to our robust Poisson regression model (table 2).

Measures of association between determinants and transfusions remained similar when an indicator of interventions with known bleeding risk was added in the
Table 1 Characteristics of participants

\begin{tabular}{|c|c|c|}
\hline Variables & $\mathbf{N}(\%)$ & $\begin{array}{l}\text { Transfused } \\
\text { with RBC } \\
\text { n (\%) }\end{array}$ \\
\hline Total & $7062(100.0)$ & $1991(28.2)$ \\
\hline \multicolumn{3}{|c|}{ 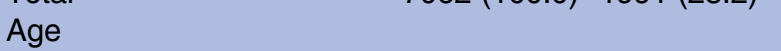 } \\
\hline $18-55$ & $4336(61.4)$ & $1346(67.6)$ \\
\hline $56-65$ & $823(11.7)$ & $252(12.7)$ \\
\hline $66-75$ & $700(9.9)$ & $174(8.7)$ \\
\hline$\geq 75$ & $1203(17.0)$ & $219(11.0)$ \\
\hline Male gender & $5168(73.2)$ & $1368(68.7)$ \\
\hline \multicolumn{3}{|l|}{ GCS on admission } \\
\hline Moderate (9-12) & $1509(21.4)$ & $278(14.0)$ \\
\hline Severe (3-8) & $1788(25.3)$ & $505(25.4)$ \\
\hline Missing & 3765 (53.3) & $1208(60.7)$ \\
\hline Intubated on arrival & 3899 (55.2) & 1249 (62.7) \\
\hline $\begin{array}{l}\text { Extracerebral trauma of } \\
\text { serious or greater severity }\end{array}$ & $3339(47.3)$ & $1417(71.2)$ \\
\hline \multicolumn{3}{|c|}{ Serious injury (AIS $\geq 3$ ) by body region } \\
\hline Head & $6682(94.6)$ & $1839(92.4)$ \\
\hline Face and neck & $598(8.5)$ & 237 (11.9) \\
\hline Thorax and abdomen & $2512(35.6)$ & $1140(57.3)$ \\
\hline Spinal & $655(9.3)$ & $286(14.4)$ \\
\hline Upper extremities & $479(6.8)$ & 257 (12.9) \\
\hline Lower extremities & $1001(14.2)$ & 635 (31.9) \\
\hline Other & $43(0.6)$ & $20(1.0)$ \\
\hline Invasive interventions* & $4201(59.5)$ & $1695(85.1)$ \\
\hline \multicolumn{3}{|l|}{ Number of comorbidities $†$} \\
\hline 0 & 5505 (78.0) & $1543(77.5)$ \\
\hline 1 & $1214(17.2)$ & $334(16.8)$ \\
\hline$\geq 2$ & $343(4.9)$ & $114(5.7)$ \\
\hline \multicolumn{3}{|c|}{ Other specific comorbidities $\ddagger$} \\
\hline Ischaemic heart disease & $172(2.4)$ & $45(2.3)$ \\
\hline Cerebrovascular disease & $114(1.6)$ & $39(2.0)$ \\
\hline Anaemia & $314(4.5)$ & $218(10.9)$ \\
\hline Coagulopathy & 89 (1.3) & $53(2.7)$ \\
\hline Sepsis & $79(1.1)$ & $39(2.0)$ \\
\hline Hypovolemic shock & $554(7.8)$ & $276(13.9)$ \\
\hline Bleeding/haemorrhage & $1701(24.1)$ & $611(30.7)$ \\
\hline Direct admission & $3586(50.8)$ & $1030(51.7)$ \\
\hline \multicolumn{3}{|l|}{ Mechanism of injury } \\
\hline MVC & 3162 (44.8) & 1237 (62.1) \\
\hline Fall & $2828(40.1)$ & $543(27.3)$ \\
\hline Other & 1072 (15.2) & $211(10.6)$ \\
\hline \multicolumn{3}{|c|}{$\begin{array}{l}\text { *See online supplementary appendix C for specific codes. } \\
\text { †Based on previous publication, }{ }^{33} \text { see online supplementary } \\
\text { appendix B. } \\
\text { †For specific comorbidities, the total of percentages may exceec } \\
100 \% \text { since they are not mutually exclusive. } \\
\text { AIS, Abbreviated Injury Severity Score; GCS, Glasgow Coma } \\
\text { Scale; MVC, motor vehicle collision; RBC, red blood cell. }\end{array}$} \\
\hline
\end{tabular}

robust Poisson model, with the exception of a reduction of the effect size of serious trauma of the lower extremities. In such model, the indicator of interventions was associated with a threefold risk of receiving a red blood cell transfusion (RR 3.00; 95\% CI 2.64 to 3.41 ).

The magnitude of the variation in the mean frequency of red blood cell transfusion among centres was estimated to $10 \%$ (95\% CI $1 \%$ to $67 \%)$. The intraclass 
Table 2 Adjusted ${ }^{\star}$ risk ratios for the association between determinants of red blood cell transfusion

\begin{tabular}{ll}
\hline Effect & Risk ratio $(95 \% \mathrm{Cl})$ \\
\hline Sex & $1.16(1.10$ to 1.23$)$ \\
Age & \\
$18-55$ & 1.00 \\
$56-65$ & $1.14(1.04$ to 1.24$)$ \\
$66-75$ & $0.96(0.84$ to 1.09$)$ \\
$\geq 75$ & $0.81(0.72$ to 0.90$)$ \\
Comorbidities & \\
0 & 1.00 \\
1 & $1.11(1.02$ to 1.21$)$ \\
$\geq 2$ & $1.66(1.40$ to 1.97$)$ \\
Other specific comorbidities considered \\
Ischaemic heart disease & $1.19(0.93$ to 1.53$)$ \\
Cerebrovascular disease & $1.17(0.95$ to 1.43$)$ \\
Anaemia & $2.10(1.81$ to 2.43$)$ \\
Coagulopathy & $1.37(1.08$ to 1.74$)$ \\
Sepsis & $1.57(1.23$ to 2.01$)$ \\
Hypovolemic shock & $1.33(1.19$ to 1.47$)$ \\
Bleeding/haemorrhage & $1.12(1.03$ to 1.22$)$ \\
Brain trauma severity & \\
Moderate TBI (GCS 9-12) & $0.78(0.70$ to 0.87$)$ \\
Serious head injury (AIS $\geq 3)$ & $0.93(0.81$ to 1.07$)$ \\
Serious extracerebral injury by anatomic region \\
Face & $1.36(1.22$ to 1.51$)$ \\
Thorax and abdomen & $1.76(1.55$ to 2.00$)$ \\
Spine & $1.24(1.08$ to 1.43$)$ \\
Upper extremities & $1.25(1.12$ to 1.40$)$ \\
Lower extremities & $1.88(1.75$ to 2.02$)$ \\
Others & $1.48(0.96$ to 2.29$)$ \\
\hline
\end{tabular}

${ }^{\text {*} A d j u s t e d ~ f o r ~ a l l ~ c o v a r i a t e s ~ i n ~ t h e ~ t a b l e . ~}$

AIS, Abbreviated Injury Severity Score; GCS, Glasgow Coma

Scale; TBI, traumatic brain injury.

correlation coefficient, calculated on the covariance parameter for centre clusters $(0.96 \pm 0.30)$ indicated that $61 \%$ of the total variation in red blood cell transfusion was accounted for by variation in practice across centres after adjustment for patient-level risk factors.

In the relative weights analyses, serious extracerebral injuries were the most important determinant of transfusion accounting for $61 \%$ of red blood cell transfusion logit variation explained by the model (figure 2). Anaemia on arrival was the most important baseline factor related to the risk of being transfused, with a relative weight of $14 \%$ (figure 2). Interventions that confer potential bleeding risk accounted for $37 \%$ of the variation when considered in the model.

\section{Clinical outcomes}

\section{Mortality}

Patients who were transfused with at least one unit of red blood cells had a significantly greater risk of death (adjusted RR 1.23; 95\% CI 1.13 to 1.33) compared with patients not transfused. The presence of comorbidities and traumatic brain injury severity were not significant modifiers of the association. Associations between red blood cell transfusion and mortality were stronger in patients $\leq 55$ years than their older counterparts (table 3).

\section{Complications}

A high proportion of patients developed complications (1361 (68\%) transfused; 2386 (47\%) non-transfused; adjusted RR 1.38 95\% CI 1.32 to 1.44). The strength of the association was greater in younger patients as well as those with moderate traumatic brain injury severity or having no comorbidity (table 3 ).

Transfusions in non-anaemic or non-bleeding patients on admission were associated with higher risks of complications. The association was not significant in patients with anaemia, and was weaker in patients who were bleeding on admission.

\section{Discharge destination}

Patients who were transfused were less often discharged home (RR 0.53 ; $95 \%$ CI 0.49 to 0.57 ). This association was significant in patients who did not have sepsis on arrival, but was not in patients with sepsis. Patients who were bleeding on arrival showed a weaker effect of transfusion on the risk of being discharged home (table 3).

\section{Length of stay}

In survivors, ICU length of stay was longer (crude mean difference: 18.63 days (95\% CI 16.64 to 20.62)) in patients who were transfused red blood cells than those who were not. After applying a correction to the length of stay for patients who died, we obtained ICU stay HRs of 1.63 (95\% CI 1.52 to 1.75 ) between patients who were transfused and those who were not, meaning that patients who were transfused had longer lengths of stay in ICU (table 3). The HR for hospital length of stay was $1.56(95 \%$ CI 1.45 to 1.67$)$, indicating a significantly longer length of stay in patients who were transfused compared with those who were not.

ICU lengths of stay were longer following transfusion in strata of non-anaemic, non-septic or non-bleeding patients. No significant differences in length of stay between transfused and non-transfused were observed in patients with anaemia or sepsis. A weaker association between transfusion and ICU length of stay was seen in patients who were bleeding on admission. Hospital lengths of stay were longer following transfusion in nonanaemic patients, but not in anaemic patients (table 3).

Patients who were transfused were ventilated for a crude mean of 4.87 more days (95\% CI 4.28 to 5.46) than those who were not. The difference remained significant in adjusted models, with adjusted geometric mean ratios of 1.87 (95\% CI 1.75 to 1.99 ).

\section{Sensitivity analyses}

All unfavourable outcomes were significantly more frequent in patients who were transfused than those who were not. The same observations were made even when adding an indicator of interventions with bleeding risk 


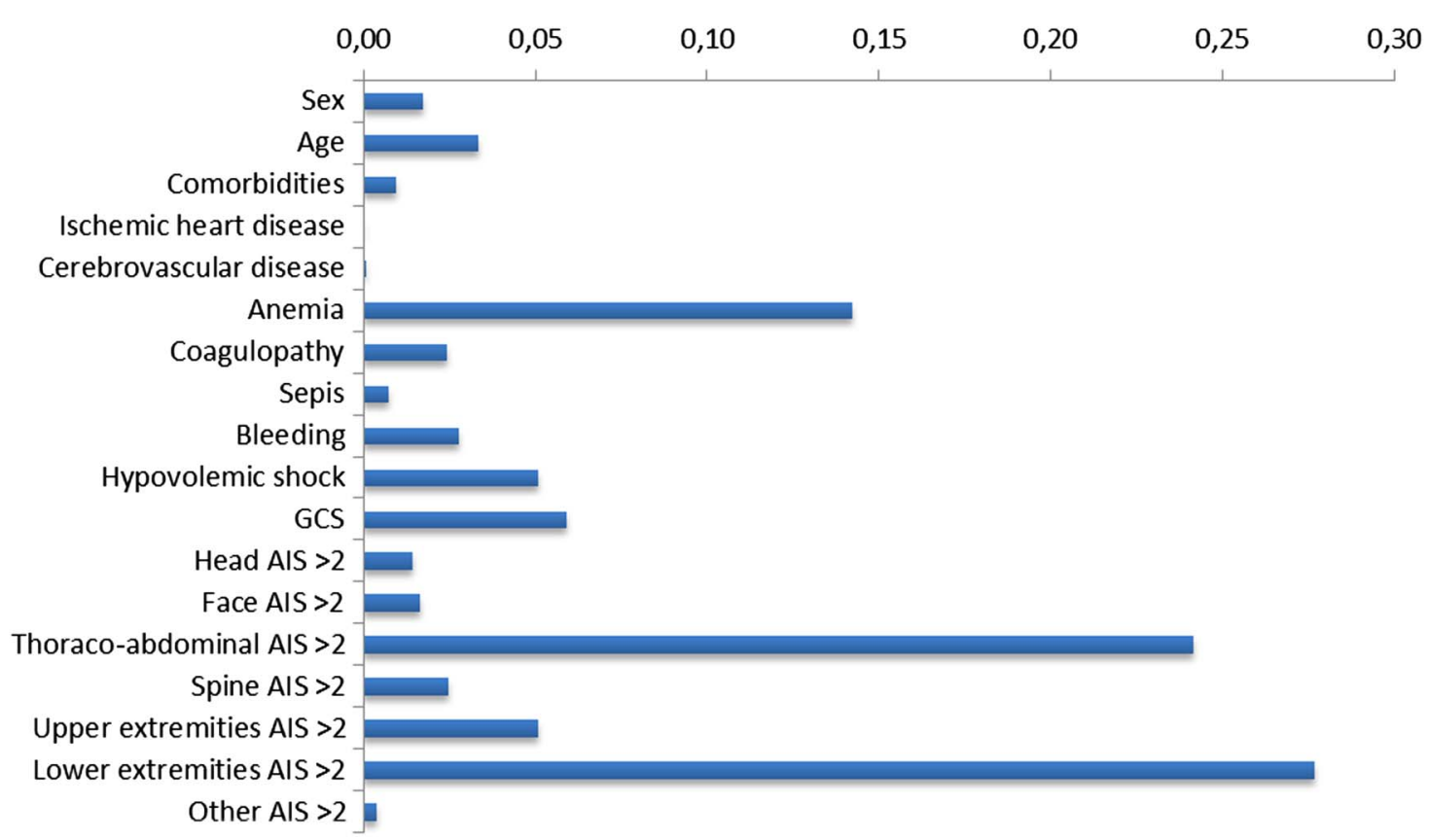

Figure 2 Potential determinants of red blood cell transfusion (the percentage represents the relative weight of each determinant in terms of the proportion of variation explained by a variable in the model).

for adjustment. Excluding patients who died within 24,48 or 72 hours, in other words limiting the analysis to those who survived at 24, 48 or 72 hours following admission, yielded stronger associations between transfusions and outcomes. Results were similar in analyses of complete observations and multiple imputations.

\section{DISCUSSION}

Across trauma hospitals in Canada, close to one-third of patients with a moderate or severe traumatic brain injury received a red blood cell transfusion during their hospital stay. Large variation in the frequency of transfusion was present across centres mainly explained by variation in practice across centres. Red blood cell transfusion was more common among patients with extracerebral trauma. After adjusting for confounding factors, patients who received at least one red blood cell transfusion experienced worse clinical outcomes, such as higher mortality, longer length of stay, more complications and discharge elsewhere than home.

The frequency of red blood cell transfusion in our cohort (28\%; $95 \%$ CI $27 \%$ to $29 \%$ ) was lower than the estimation from our recent systematic review $(36 \% ; 95 \%$ CI $28 \%$ to $44 \%) .{ }^{20}$ In both studies, frequencies varied greatly between healthcare settings. Since centre variation remained high when evaluating determinants of red blood cell transfusion, regional practice variations may account for a large part of variations observed in absence of clear consensus. Variability in practices across centres has been previously observed in a large cohort of patients with traumatic brain injury looking at withdrawal of life-sustaining therapy, ${ }^{6}$ another domain in which data is scarce.

As we observed previously in our systematic review, ${ }^{19}$ patients with anaemia on admission were at a higher risk of receiving red blood cell transfusion. This is likely due to the fact that haemoglobin usually drops over an ICU stay and red blood cell transfusions are administered with the intention of increasing haemoglobin level and thus oxygen delivery. ${ }^{24} 40-43$ Active bleeding on arrival and hypovolemic shock, which can also result from major rapid blood loss, were associated with red blood cell transfusion. Although such conditions are often treated with volume replacement using crystalloids, ${ }^{44} 45$ early red blood cell transfusion is frequently used as it is included in developed protocols of care for massive transfusion following evidence of benefit from early transfusion of blood products in these situations. ${ }^{44}$ Considering the high frequency of major bleeding from serious thoraco-abdominal wounds and lower limb fractures, ${ }^{46} 47$ it is unsurprising that those type of injuries were also associated with higher incidence proportions of red blood cell transfusion. Sepsis was also associated with transfusions in our cohort. It is another factor associated with loss of erythrocytes and also with the limited ability to extract oxygen from blood. In this context, higher haemoglobin levels have been advocated in this population. ${ }^{48}$ However, no strong evidence supports this approach. ${ }^{49} 50$ Transfusions were also more frequent in patients with coagulopathy. Even if red blood cell preparations do not include coagulation factors and cannot treat coagulopathy, patients presenting with the latter condition tend to experience prolonged bleeding. Early red blood cell transfusion following trauma might 
Table 3 Adjusted* ${ }^{*}$ risk ratios and HRs of outcomes according to the transfusion status

\begin{tabular}{|c|c|c|c|c|c|c|}
\hline & N (\%) & $\begin{array}{l}\text { Mortality, adjusted risk } \\
\text { ratios }(95 \% \mathrm{Cl})\end{array}$ & $\begin{array}{l}\text { Complications, adjusted } \\
\text { risk ratios }(95 \% \mathrm{Cl})\end{array}$ & $\begin{array}{l}\text { ICU stay, adjusted } \\
\text { HRs† }(95 \% \mathrm{Cl})\end{array}$ & $\begin{array}{l}\text { Hospital stay, adjusted } \\
\text { HRs† }(95 \% \mathrm{Cl})\end{array}$ & $\begin{array}{l}\text { Discharged home, adjusted } \\
\text { risk ratios }(95 \% \mathrm{Cl})\end{array}$ \\
\hline Overall & 7062 & $1.23(1.13$ to 1.33$)$ & 1.38 (1.32 to 1.44$)$ & $1.63(1.52$ to 1.75$)$ & 1.56 (1.45 to 1.67$)$ & 0.53 (0.49 to 0.57$)$ \\
\hline \multicolumn{7}{|l|}{ Strata } \\
\hline \multicolumn{7}{|l|}{ Age } \\
\hline $18-55$ & $4336(61.40)$ & 1.54 (1.37 to 1.73$)$ & 1.55 (1.44 to 1.66$)$ & $1.06(0.85$ to 1.33$)$ & $1.67(1.53$ to 1.81$)$ & $0.53(0.48$ to 0.58$)$ \\
\hline $56-65$ & $823(11.65)$ & $1.10(0.94$ to 1.28$)$ & $1.26(1.15$ to 1.38$)$ & 1.79 (1.65 to 1.94$)$ & $1.24(1.02$ to 1.50$)$ & $0.46(0.30$ to 0.71$)$ \\
\hline $66-75$ & 700 (9.91) & $1.00(0.84$ to 1.19$)$ & 1.18 (1.05 to 1.32$)$ & $1.38(1.14$ to 1.68$)$ & $1.45(1.15$ to 1.83$)$ & 0.55 (0.30 to 1.02$)$ \\
\hline$\geq 75$ & $1203(17.03)$ & 0.94 (0.78 to 1.13$)$ & 1.13 (1.01 to 1.26$)$ & 1.31 (1.04 to 1.66$)$ & 1.26 (1.01 to 1.58$)$ & 0.60 (0.35 to 1.03$)$ \\
\hline \multicolumn{7}{|c|}{ 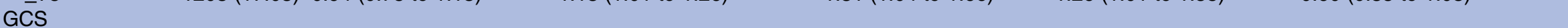 } \\
\hline Moderate & $1788(25.32)$ & 1.21 (0.98 to 1.49$)$ & 1.55 (1.37 to 1.75$)$ & 1.80 (1.60 to 2.02$)$ & $1.61(1.43$ to 1.80$)$ & 0.53 (0.44 to 0.63$)$ \\
\hline Severe & 1509 (21.37) & $1.23(1.12$ to 1.36$)$ & 1.33 (1.27 to 1.39$)$ & 1.53 (1.40 to 1.67$)$ & $1.53(1.40$ to 1.67$)$ & $0.52(0.47$ to 0.59$)$ \\
\hline \multicolumn{7}{|l|}{ Comorbidities } \\
\hline 0 & 5505 (77.95) & 1.27 (1.16 to 1.39$)$ & 1.42 (1.36 to 1.49$)$ & $1.67(1.55$ to 1.81$)$ & $1.60(1.48$ to 1.74$)$ & 0.51 (0.47 to 0.56$)$ \\
\hline 1 & $1214(17.19)$ & $1.18(0.98$ to 1.42$)$ & 1.33 (1.19 to 1.48$)$ & 1.51 (1.28 to 1.79$)$ & 1.41 (1.20 to 1.66$)$ & 0.51 (0.37 to 0.69$)$ \\
\hline$\geq 2$ & $343(4.86)$ & $0.97(0.74$ to 1.26$)$ & $1.07(0.92$ to 1.24$)$ & $1.29(0.95$ to 1.74$)$ & 1.35 (0.99 to 1.82$)$ & $0.87(0.50$ to 1.51$)$ \\
\hline \multicolumn{7}{|c|}{ Specific comorbidities } \\
\hline Anemic & $314(4.45)$ & $1.00(0.72$ to 1.40$)$ & $1.00(0.88$ to 1.13$)$ & $1.17(0.87$ to 1.57$)$ & $0.95(0.71$ to 1.28$)$ & 0.65 (0.48 to 0.88$)$ \\
\hline Non-anemic & $6748(95.55)$ & $1.23(1.14$ to 1.33$)$ & $1.38(1.33$ to 1.44$)$ & $1.62(1.51$ to 1.75$)$ & 1.55 (1.43 to 1.67$)$ & $0.52(0.48$ to 0.57$)$ \\
\hline Septic & $79(1.12)$ & 0.36 (0.09 to 1.46$)$ & $1.11(0.87$ to 1.42$)$ & $0.90(0.54$ to 1.50$)$ & $2.11(1.27$ to 3.51$)$ & $1.52(0.72$ to 3.19$)$ \\
\hline Non-septic & $6983(98.88)$ & $1.23(1.14$ to 1.34$)$ & 1.37 (1.31 to 1.42$)$ & $1.61(1.49$ to 1.73$)$ & $1.50(1.39$ to 1.61$)$ & $0.52(0.48$ to 0.57$)$ \\
\hline Bleeding & $1701(24.09)$ & 1.15 (0.93 to 1.42$)$ & $1.18(1.08$ to 1.30$)$ & $1.36(1.20$ to 1.55$)$ & $1.47(1.29$ to 1.67$)$ & 0.67 (0.55 to 0.82$)$ \\
\hline Non-bleeding & $5361(75.91)$ & 1.25 (1.15 to 1.36$)$ & 1.44 (1.39 to 1.50$)$ & 1.68 (1.55 to 1.83$)$ & $1.52(1.40$ to 1.65$)$ & $0.50(0.46$ to 0.54$)$ \\
\hline
\end{tabular}

*Adjusted for sex, age, comorbidities, GCS, head AIS, square of max extracerebral AIS.

†With death considered as censored at the longest length of stay; value $>1$ indicates that patients were at lower risk of being discharge alive (longer stays) and $<1$ at higher risk (shorter stays). AIS, Abbreviated Injury Severity Score; GCS, Glasgow Coma Scale. 
beneficially reduce the risk of coagulopathy. ${ }^{51}$ Furthermore, trauma-induced coagulopathy increases the risk of major bleeding and use of 1:1:1 platelet:fresh frozen plasma:red blood cell has been advocated by some experts in the prevention or treatment of trauma-induced coagulopathy. However, few evidences support the use of such strategy. ${ }^{52}{ }^{53}$ When added to the model, surgical interventions were associated with transfusions. Trauma surgeries can lead to important blood loss, or be initiated in order to control haemorrhage.

We observed worse outcomes in patients who received at least one red blood cell transfusion, which is similar to the results of previous studies. ${ }^{54-57}$ When we stratified analyses by anaemic status, the effect of transfusion on complications, and ICU and hospital length of stay were different. Specifically, transfused patients in the nonanaemic strata had significantly higher risk of worse outcome and no such relationship was observed in patients who were anaemic on admission. This is similar to the observations of previous studies, ${ }^{54} 57$ and illustrates again the importance of considering haemoglobin levels when evaluating the association between red blood cell and patient-oriented outcomes in the context of traumatic brain injury. A recent $\operatorname{trial}^{26}$ failed to observe significant differences over mortality and neurological outcome but was underpowered and not designed to evaluate equivalency of such outcomes. Further analyses of the progressive decline in haemoglobin during ICU stay, pretransfusion haemoglobin level and its impact on optimal transfusion strategies are needed.

Similarly, sepsis was also a modifying factor of the effect of red blood cell transfusion on clinical outcomes. According to our observations, red blood cell transfusion showed neither significant benefit nor disadvantage over clinical outcomes when patients were in sepsis (except for hospital length of stay), but tended to be associated with worse outcomes in patients who did not have sepsis diagnosed on arrival. According to previous studies comparing liberal to restrictive transfusion strategies in populations of septic patients, similar outcomes were observed for both strategies ${ }^{49}$ leading clinical guidelines to support restrictive use of red blood cell in the treatment of severe sepsis and septic shock. ${ }^{58}$ As mentioned earlier, patients with sepsis often show decreasing levels of haemoglobin and a reduced ability to extract oxygen from blood. The apparent equivalency between groups of patients who did or did not receive red blood cell in this stratum could be related to important haemoglobin depletion, requiring further investigation of haemoglobin levels.

\section{Strengths and limitations}

Level I and II trauma centres across the country are well represented in the registry, and patients with moderate or severe traumatic brain injury are rarely treated outside highly specialised centres. ${ }^{59-61}$ Therefore, undercoverage from patients being treated in trauma centres that are not included in the registry or in non-trauma centres should not have had a major effect on our frequency estimate. However, we could not link $21.9 \%$ of the National Trauma Registry to the Discharge Abstract Database. Considering that the province of Québec does not contribute to the Discharge Abstract Database of the National Trauma Registry, and that its population represents $23 \%$ of Canada's population, we can estimate that our study population represents trauma patients in Canada, with the exception of those from the province of Québec. Considering that training of physicians and certifications of trauma centres are managed at a national Canadian level, healthcare delivery is thus likely to be consistent across provinces. More so, referral and triage being independent in each Canadian province, the distribution of trauma severity would thus not be affected by the absence of data from one province. Our study was inclusive and we had a large sample size, and therefore high power. Our statistical plan was strong, with advanced biostatistics methods and conceptual rigour. We used multilevel models, with random effects. This method allowed to account for potential differences in local practices (between centres) in our evaluation of red blood cell transfusions and its potential determinants, as well as associated outcomes. We explored a large spectrum of a priori conceptual models of the potential relationship between transfusions and clinical variables, which we explored with multiple sensitivity and subgroup analyses. Although residual confounding remains a concern, we optimised control for potential bias through multivariate analyses.

Secondary data use has the risk of measurement bias/ misclassification and incompleteness of data. However, data quality is monitored by The Canadian Institute for Health Information ${ }^{62}$ assuring a high reliability of data collection and encoding ${ }^{63}$ and limiting the potential for such errors. It is possible that incomplete assessment of comorbidities, extracerebral injuries and interventions contributed to the underestimation of their frequencies and effect sizes. For example, comorbidity capture depends on what was noted in the hospital chart and may not represent an exhaustive account of all comorbidities present in a given patient at the time of admission. Even with the inclusion of comorbidities as potential confounders in our models of patient-oriented outcomes, residual confounding is possibly present. Similarly, complications are reported differently across trauma centres, screening and coding practices may vary greatly, causing incomplete outcome measurement. Any under-reporting should not be systematically linked to transfusion practices, but may bias our estimates. Furthermore, we had limited information on traumatic brain injury severity, as GCS scores were often missing and the registry do not contain data on clinical findings such as pupillary reflex, which is another indicator of severity and prognostic variable in traumatic brain injury. Although we endeavoured to overcome this limitation with multiple imputation and included information on 
severity of head trauma (head AIS) in our models, adjustment might still be imperfect.

We did not have data on the quantity of red blood cell units transfused or number of transfusion events. As such, a dose-response relationship could not be evaluated. We also did not have information on haemoglobin levels during hospitalisation, which would have been a more precise measure of the status of the patient than simply the presence of anaemia on admission. We could not evaluate the effect of transfusion strategies (transfusion at different haemoglobin levels).

Owing to the use of secondary data, we could not properly identify and control timing and reasons for identified surgical interventions, so both causal mechanisms are plausible (ie, interventions could increase the risk of transfusions and transfusions might increase the risk of interventions as well). For this reason, we kept adjustment to baseline variables. However, when we added the indicator of interventions, our results remained similar. Furthermore, the registry does not contain information on timing of complications either and thus, we cannot exclude that complications might have contributed to decision to transfuse rather than resulted from it. We were also limited on variables to control for by data available in the registry (eg, data on decisions over the goals of care are not reported), resulting in potential residual confounding. Overall, due to our limited ability to control for factors related to the need or decision to transfuse and clinical outcomes (such as severity of trauma, comorbidities, complications directly related with the trauma, decisions on intensity of care, other interventions), we cannot exclude confounding by indication.

\section{CONCLUSION}

In our multicentre cohort study, we observed that red blood cell transfusions were frequent in patients with traumatic brain injury and varied considerably between centres. Trauma severity and invasive interventions are important determinants of transfusion decisions. More so, red blood cell transfusion was associated with increased mortality, prolonged ICU and hospital length of stay and adverse events. However, these associations are potentially confounded considering that transfusions are correlated to worse clinical baseline prognosis, which we could not fully account for in the analyses. Prospective trials are required to better understand the impact of different transfusion strategies on clinical outcomes in which to inform future trials of optimal transfusion strategy for traumatic brain injury.

\section{Author affiliations}

${ }^{1}$ Population Health and Optimal Health Practices Research Unit (TraumaEmergency-Critical Care Medicine), CHU de Québec-Université Laval Research Centre, Université Laval, Québec, Québec, Canada

2Department of Social and Preventive Medicine, Université Laval, Québec, Québec, Canada

${ }^{3}$ Department of Anesthesiology and Critical Care Medicine, Division of Critical Care Medicine, Université Laval, Québec, Québec, Canada
${ }^{4}$ Clinical Epidemiology Unit, Ottawa Hospital Research Institute, Ottawa, Ontario, Canada

${ }^{5}$ Department of Internal Medicine, Sections of Critical Care Medicine, of Haematology and of Medical Oncology, University of Manitoba, Winnipeg, Manitoba, Canada

${ }^{6}$ Department of Anesthesia, University of British Columbia, Vancouver, British Columbia, Canada

Acknowledgements The authors want to thank Caroline Léger PhD, Michele Shemilt MSc and Marie-Joëlle Cossi PhD for their administrative help with this study and manuscript.

Contributors $A B, L M 0, F L, M C, R Z, D A F$ and AFT were involved in the conception and design. $A B, L M o$ and $A F T$ were involved in the acquisition. $A B, L M o, F L, M C, S E, R Z, L M c, D G D A F$ and AFT were involved in the interpretation of data. $A B, L M o$ and $A F T$ drafted the manuscript. $A B, L M o, F L$, $M C, S E, R Z, L M c, D G, D A F$ and AFT were involved in revising the manuscript and approved the version published.

Funding $A B$ is recipient of a Frederick Banting and Charles Best Canada Graduate Scholarships Doctoral Award from the Canadian Institutes of Health Research (CIHR). LM, AFT and RZ are/were recipients of New Investigator Awards from the CIHR. AFT and FL are supported by the Traumatology Research Consortium of the Fonds de Recherche du Québec-Santé (FRQS). $\mathrm{FL}$ is a recipient of a salary support Award from the FRQS. AFT is the Canada Research Chair in Critical Care Neurology and Trauma.

Competing interests None declared.

Ethics approval The study received ethics approval by $\mathrm{CHU}$ de QuébecUniversité Laval.

Provenance and peer review Not commissioned; externally peer reviewed.

Data sharing statement No additional data are available.

Open Access This is an Open Access article distributed in accordance with the Creative Commons Attribution Non Commercial (CC BY-NC 4.0) license, which permits others to distribute, remix, adapt, build upon this work noncommercially, and license their derivative works on different terms, provided the original work is properly cited and the use is non-commercial. See: http:// creativecommons.org/licenses/by-nc/4.0/

\section{REFERENCES}

1. Maas Al, Stocchetti N, Bullock R. Moderate and severe traumatic brain injury in adults. Lancet Neurol 2008;7:728-41.

2. Ruttan L, Martin K, Liu A, et al. Long-term cognitive outcome in moderate to severe traumatic brain injury: a meta-analysis examining timed and untimed tests at 1 and 4.5 or more years after injury. Arch Phys Med Rehabil 2008;89(12 Suppl):S69-76.

3. Andelic N, Sigurdardottir S, Schanke AK, et al. Disability, physical health and mental health 1 year after traumatic brain injury. Disabil Rehabil 2010;32:1122-31.

4. Mclntyre A, Mehta S, Janzen S, et al. A meta-analysis of functional outcome among older adults with traumatic brain injury. NeuroRehabilitation 2013;32:409-14.

5. Centers for Disease Control and Prevention. Report to congress on traumatic brain injury in the United States: epidemiology and rehabilitation. Atlanta, GA: National Center for Injury Prevention and Control; Division of Unintentional Injury Prevention, 2014.

6. Turgeon AF, Lauzier F, Simard JF, et al. Mortality associated with withdrawal of life-sustaining therapy for patients with severe traumatic brain injury: a Canadian multicentre cohort study. CMAJ 2011;183:1581-8.

7. Fu TS, Jing R, McFaull SR, et al. Health \& economic burden of traumatic brain injury in the Emergency Department. Can J Neurol Sci 2016;43:238-47.

8. Hyder AA, Wunderlich CA, Puvanachandra $P$, et al. The impact of traumatic brain injuries: a global perspective. NeuroRehabilitation 2007;22:341-53.

9. Kramer AH, Zygun DA. Anemia and red blood cell transfusion in neurocritical care. Crit Care 2009;13:R89.

10. Bellapart J, Boots R, Fraser J. Physiopathology of anemia and transfusion thresholds in isolated head injury. $J$ Trauma Acute Care Surg 2012;73:997-1005. 
11. Sena MJ, Rivers RM, Muizelaar JP, et al. Transfusion practices for acute traumatic brain injury: a survey of physicians at US trauma centers. Intensive Care Med 2009;35:480-8.

12. Raghavan M, Marik PE. Anemia, allogenic blood transfusion, and immunomodulation in the critically ill. Chest 2005;127:295-307.

13. Carson JL, Carless PA, Hebert PC. Transfusion thresholds and other strategies for guiding allogeneic red blood cell transfusion. Cochrane Database Syst Rev 2012;(4):CD002042.

14. Carson JL, Grossman BJ, Kleinman S, et al. Red blood cell transfusion: a clinical practice guideline from the AABB* Ann Intern Med 2012;157:49-58

15. Utter GH, Shahlaie K, Zwienenberg-Lee M, et al. Anemia in the setting of traumatic brain injury: the arguments for and against libera transfusion. J Neurotrauma 2011;28:155-65.

16. Kramer AH, Le Roux P. Red blood cell transfusion and transfusion alternatives in traumatic brain injury. Curr Treat Options Neurol 2012;14:150-63.

17. Roberts DJ, Zygun DA. Anemia, red blood cell transfusion, and outcomes after severe traumatic brain injury. Crit Care 2012;16:154.

18. Mirski MA, Frank SM, Kor DJ, et al. Restrictive and liberal red cell transfusion strategies in adult patients: reconciling clinical data with best practice. Crit Care 2015;19:202.

19. Boutin A, Chasse M, Shemilt M, et al. Red blood cell transfusion in patients with traumatic brain injury: a systematic review and meta-analysis. Transfus Med Rev 2016;30:15-24.

20. Desjardins P, Turgeon AF, Tremblay MH, et al. Hemoglobin levels and transfusions in neurocritically ill patients: a systematic review of comparative studies. Crit Care 2012;16:R54

21. Veenith T, Sharples L, Gerrard C, et al. Survival and length of stay following blood transfusion in octogenarians following cardiac surgery. Anaesthesia 2010;65:331-6.

22. Chant C, Wilson G, Friedrich JO. Anemia, transfusion, and phlebotomy practices in critically ill patients with prolonged ICU length of stay: a cohort study. Crit Care 2006;10:R140

23. Andersen J, Sharkey W, Schwartz ML, et al. Injury severity score, head injury, and patient wait days: contributions to extended trauma patient length of stay. J Trauma 1992;33:219-20.

24. Marik PE, Corwin HL. Efficacy of red blood cell transfusion in the critically ill: a systematic review of the literature. Crit Care Med 2008;36:2667-74.

25. McIntyre LA, Fergusson DA, Hutchison JS, et al. Effect of a liberal versus restrictive transfusion strategy on mortality in patients with moderate to severe head injury. Neurocrit Care 2006;5:4-9.

26. Robertson CS, Hannay HJ, Yamal JM, et al. Effect of erythropoietin and transfusion threshold on neurological recovery after traumatic brain injury: a randomized clinical trial. JAMA 2014;312:36-47.

27. von Elm E, Altman DG, Egger M, et al. The Strengthening the Reporting of Observational Studies in Epidemiology (STROBE) statement: guidelines for reporting observational studies. PLoS Med. 2007;4:e296.

28. Gennarelli TA, Wodzin E. AIS 2005: a contemporary injury scale. Injury 2006;37:1083-91.

29. Charlson ME, Pompei P, Ales KL, et al. A new method of classifying prognostic comorbidity in longitudinal studies: development and validation. J Chronic Dis 1987;40:373-83.

30. Moore L, Lavoie A, Le Sage N, et al. Using information on preexisting conditions to predict mortality from traumatic injury. Ann Emerg Med 2008;52:356-64.e2.

31. Moore L, Lauzier F, Stelfox HT, et al. Complications to evaluate adult trauma care: an expert consensus study. $J$ Trauma Acute Care Surg 2014;77:322-9; discussion 9-30.

32. Moore L, Lauzier F, Stelfox HT, et al. Validation of complications selected by consensus to evaluate the acute phase of adult trauma care: a multicenter cohort study. Ann Surg 2015;262:1123-9.

33. Zou G. A modified poisson regression approach to prospective studies with binary data. Am J Epidemiol 2004;159:702-6.

34. Tonidandel S, LeBreton JM. Determining the relative importance of predictors in logistic regression: an extension of relative weight analysis. Organ Res Methods 2010;13:767-81.

35. Rosenbaum PR. The place of death in the quality of life. Stat Sci 2006;21:313-6.

36. Halpern SD, ed. ICU length of stay: a new approach to a challenging outcome. Toronto: Canadian Critical Care Forum, 2012.

37. Brock GN, Barnes C, Ramirez JA, et al. How to handle mortality when investigating length of hospital stay and time to clinical stability. BMC Med Res Methodol 2011;11:144.
38. Moore L, Hanley JA, Turgeon AF, et al. A multiple imputation model for imputing missing physiologic data in the national trauma data bank. J Am Coll Surg 2009;209:572-9.

39. Moore L, Hanley JA, Lavoie A, et al. Evaluating the validity of multiple imputation for missing physiological data in the national trauma data bank. J Emerg Trauma Shock 2009;2:73-9.

40. Corwin HL, Gettinger A, Pearl RG, et al. The CRIT Study: anemia and blood transfusion in the critically ill--current clinical practice in the United States. Crit Care Med 2004;32:39-52.

41. Rawn J. The silent risks of blood transfusion. Curr Opin Anaesthesiol 2008;21:664-8.

42. Chargé S, ed. Clinical guide to transfusion medicine. 5th edn. Canada: Canadian Blood Services, 2013.

43. Spinelli E, Bartlett RH. Anemia and transfusion in critical care: physiology and management. J Intensive Care Med 2016;31:295-306.

44. Juffermans NP, Walsh TS. Transfusion in the intensive care unit. Switzerland: Springer International Publishing, 2015.

45. McCullough JJ. Transfusion medicine. Chichester, UK: Wiley-Blackwell, 2012.

46. Evans JA, van Wessem KJ, McDougall D, et al. Epidemiology of traumatic deaths: comprehensive population-based assessment. World J Surg 2010;34:158-63.

47. Yucel N, Lefering R, Maegele M, et al. Trauma Associated Severe Hemorrhage (TASH)-Score: probability of mass transfusion as surrogate for life threatening hemorrhage after multiple trauma. J Trauma 2006;60:1228-36; discussion 36-7.

48. Juffermans NP, Walsh TS. Transfusion in the intensive care unit. Switzerland: Springer International Publishing, 2015.

49. Holst LB, Haase N, Wetterslev J, et al. Lower versus higher hemoglobin threshold for transfusion in septic shock. N Engl J Med 2014;371:1381-91.

50. Marik PE. Early management of severe sepsis: concepts and controversies. Chest 2014;145:1407-18.

51. Brown JB, Cohen MJ, Minei JP et al. Pretrauma center red blood cell transfusion is associated with reduced mortality and coagulopathy in severely injured patients with blunt trauma. Ann Surg 2015;261:997-1005.

52. Hallet J, Lauzier F, Mailloux O, et al. The use of higher platelet: RBC transfusion ratio in the acute phase of trauma resuscitation: a systematic review. Crit Care Med 2013;41:2800-11.

53. Holcomb JB, Tilley BC, Baraniuk S, et al. Transfusion of plasma, platelets, and red blood cells in a 1:1:1 vs a 1:1:2 ratio and mortality in patients with severe trauma: the PROPPR randomized clinical trial. JAMA 2015;313:471-82.

54. Elterman J, Brasel K, Brown S, et al. Transfusion of red blood cells in patients with a prehospital Glasgow Coma Scale score of 8 or less and no evidence of shock is associated with worse outcomes. J Trauma Acute Care Surg 2013;75:8-14; discussion.

55. Yang CJ, Hsiao KY, Su IC, et al. The association between anemia and the mortality of severe traumatic brain injury in emergency department. J Trauma 2011;71:E132-E5.

56. Warner MA, O'Keeffe T, Bhavsar $P$, et al. Transfusions and long-term functional outcomes in traumatic brain injury. J Neurosurg 2010;113:539-46.

57. Salim A, Hadjizacharia $P$, DuBose $\mathrm{J}$, et al. Role of anemia in traumatic brain injury. J Am Coll Surg 2008;207:398-406.

58. Dellinger RP, Levy MM, Rhodes A, et al. Surviving sepsis campaign: international guidelines for management of severe sepsis and septic shock: 2012. Crit Care Med 2013;41:580-637.

59. Institut National d'Excellence en Santé et en Services sociaux (INESSS). Avis sur les critères de triage préhospitalier en traumatologie. Rapport rédigé par André Lavoie en collaboration avec Gilles Bourgeois et Jean Lapointe. ETMIS, 2013:1-46.

60. Sasser SM, Hunt RC, Faul M, et al., Centers for Disease Control and Prevention. Guidelines for field triage of injured patientsrecommendations of The National Expert Panel on Field Triage, 2011. MMWR Recomm Rep 2012;61(RR-1):1-20.

61. Kuimi BL, Moore L, Cisse B, et al. Access to a Canadian provincial integrated trauma system: a population-based cohort study. Injury 2015;46:595-601.

62. Canadian Insitute for Health Information. National trauma registry comprehensive data set-data quality summary for external users. Ottawa, Ontario: Canadian Institute for Health Information-Institut canadian de l'information sur la santé (CIHI-ICIS), 2014.

63. Canadian Insitute for Health Information. $\mathrm{ClHI}$ data quality study of the 2009-2010: discharge abstract database. CIHI-ICIS, 2012 (cited 2012). https://secure.cihi.ca/free products/Reabstraction june19revised_09_10_en.pdf 